\author{
Multidisciplinary \\ SCIENTIFIC JOURNAL OF \\ MARITIME RESEARCH
}

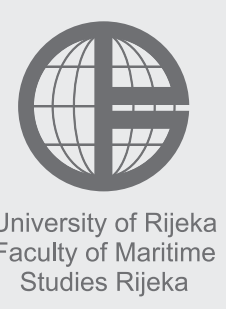

Multidisciplinarni

znanstveni časopis

POMORSTVO

\title{
Structural changes in the container liner shipping influencing shipping agent's role
}

\author{
Bojan Beškovnik \\ University of Ljubljana, Faculty of Maritime Studies and Transportation, Pot pomorščakov 4, 6320 Portorož, Slovenia, e-mail: bojan.beskovnik@fpp.uni-lj.si
}

\section{ABSTRACT}

The article presents structural changes in liner shipping sector, as many global Container shipping lines are opening their own agencies and many independent shipping agents are consecutively closing down their activities, either via takeovers or by going out of business completely. The process of horizontal and vertical integration in shipping industry is re-shaping the entire logistics industry. Such changes put pressure on shipping agents to redefine their market role and develop services with added quality, and relationships with actual and new principals. They are forced to seek for new ways to make income therefore they are forced to perform additional roles, in order to satisfy carriers on one hand, and usually just a few clients, on the other. A market analysis in Slovenia has been performed among companies offering ship-port services, with focus on comparison between independent agents and Container Line offices. It has been ascertained that independent shipping agents must implement the new strategy which is closer to a forwarder's mentality and market role.
\end{abstract}

\section{ARTICLE INFO}

Preliminary communication Received 6 November 2014

Accepted 24 September 2016

\section{Key words:}

Maritime industry

Shipping line

Shipping agent

Horizontal integration

Ship-port operations

\section{Introduction}

The shipping industry is facing tough times, as the global industry is still under pressure of considerable fall in global production and consumption. Undoubtedly, the shipping sector is suffering from the global financial and economic crisis, and elements as efficient time managing, managing space and information in global supply chains are becoming the key goals of all participating subjects in the supply chain. Such focus highlights the need of some structural changes and reorganization within the entire sector.

For this reason, the entire shipping industry is entering the new era of building modern logistics, with an aim to gather the entire supply chain under one umbrella. Container shipping lines are introducing the horizontal and vertical integration in the shipping sector (Notteboom and Merckx, 2006), where the traditional role of a shipping agent is slowly disappearing. In particular, this is the case with strong economies or port areas where ports are those of the principal intermodal transit points.

The first, and fundamental, intervening act in a Container Line's organization is to cut the number of sub- jects that are involved in a supply chain. Frémont (2009) exposes that such a vertical integration strategy bases on providing efficient and direct support to vessel logistics. As a result, both the independent shipping agent and forwarding agent are under pressure to find a new way of income and secure their own financial means for a certain period of time. The field of shipping agency is therefore in an extremely delicate stage, where only some of agents will have the possibility for further existence and development.

Although this is an important topic for the shipping sector, the shipping agent management has seen very little research so far which has been affirmed also by GonzálezTorre et al. (2013) in their study of the fundamental characteristics of shipping agents, through an operation's strategy alignment and strategic contingency theory lens. Moreover, Debelic (2013) exposes different views on agency theory and agency application that are to some extent in conflict interactions. A lack of researches and the strong re-organization of shipping agency market encourage the need to analyse the situation in a rather limited market in Slovenia, where Port of Koper represents an important 
transit port for markets in Central Europe. The analysis includes 36 companies which are offering shipping agency services. Of these, 22 companies do not offer forwarding services on the market, but they are primarily focused on ship-port services.

\section{Structural changes influencing shipping agency organization}

\subsection{Strong horizontal and vertical integration}

In the past 50 years the shipping industry went through different horizontal and vertical integration processes. Containerisation even speeded-up this process as it became the backbone of new logistics concepts (Brooks, 2000). Frémont (2008) exposes the fact that containerisation redesigned transport chains through horizontal and vertical integration in shipping industry. Nowadays, the container shipping lines operate port terminals, hinterland terminals and organize shuttle trains on main transport routes. According to Notteboom and Merckx (2006) many shipping lines have already developed a keen interest in other segments of the logistics and transportation market to offer integrated logistics services. Such re-structuring processes limit niche players, as shipping agents are, in their traditional role.

Namely, a traditional supply chain consists of seven to nine subjects, such as a supplier, a forwarding agent, customs broker, a ship agent at a loading port, a shipping line, a ship agent at a port of discharge, a customs broker, a consignee's forwarding agent and finally, a consignee. All these parties must work as a synchronous group of subjects in order to provide a lean transport process (Lyridis et al., 2007). With the horizontal integration the entire supply chain of containerised goods can be organized by only three subjects - a supplier, a consignee and a container shipping line, where the goal to achieve a synchronized and coordinated action is much easier to achieve and also control the entire door-to-door supply chain. Container shipping lines expand their product portfolio by offering pre-carriage transport up to port of loading, ocean transportation and on-carriage transport from port of discharge up to the final destination. The entire logistics chain is supported by IT programs that allow track and trace service per a single container to the shipper and consignee. Of course, the Container line must have presence in port of loading and port of discharge and in some cases also in hinterland markets. The entire operational procedure along supply chain is secured by the Line.

Such organisation permits Container lines to have a lean internal organization and one-stop shop for serving their customers. Such an approach became a practice in developed economies, influencing the traditionally organized shipping agency market. Heaver (2002) sees different advantages of such an integration of logistics operations under the container line's control and organization. Besides the lean communication flow, there are also other benefits, such as lower costs on the entire route due to the economy of scale, fewer contracts between the involved parties, easier and lean coordination activities, etc.

The described integration in container shipping and logistics industry influences the shipping agency sector, especially those companies that play in the market as independent ship agents. Namely, in western economies, across the U.S.A., throughout Western Europe and in Asia, independent shipping agents are slowly disappearing (Zhizhong, 2007). On one hand the reasons are the takeovers by ship carriers, and on the other they are forced to go out of business, as they have not been able to establish new ways of making an income, or they reorganize themselves by turning into forwarding agents (Philips, 2005). Thus the numbers of small and mediumsized independent shipping agencies are dropping steadily (Frémont, 2008). In some traditional shipping markets, like Scandinavia, the Baltic region and Greece as well, the quantities of independent agents are still very high, even all the biggest container shipping lines are present with own local agencies.

\subsection{Shipping agencies with a joint venture agreement with Principals}

In the shipping sector there is the trend to make joint venture agreements between ship carriers or container shipping lines and shipping agents. Such cooperation gives a certain amount of comfort to both parties. Principals get a reliable ship agent with an influence on key managerial elements and future strategy of development. On the other hand, a ship agent secures the key client, market and regular income.

However, Heaver et al. (2000) claim that there is no guarantee for a durable cooperation even with the jointventure agreement. Namely, with mergers carried out between the Principals, shipping agents can lose a principal to represent overnight. The agency agreement between the Principal and an agent usually includes a 90 to 180 days cancellation clause, but in such a case the period can be even shorter. Consequently, an agent is always under the pressure of agreement and business termination. Moreover, the substitution of an agency agreement is not easy and it takes quite a long period of time to find a new business on the limited market.

Besides all disadvantages, the advantage of a joint venture agreement is evident for an agent. It secures regular business, lean internal structure and processes and also regular and highest income. Consequently, the sales activity is mostly oriented on the market to find new clients for "home" container liner service, as there is no need to constantly look for an alternative Principal to represent. Namely, lean internal structure basis on less accounting staff, less commercial or sales personnel and reduced IT costs. Besides important positive benefits a joint venture secures, the impact of negative elements has to be taken into consideration as well. The shipping agency that op- 
erates on joint-venture cooperation faces difficulties in achieving different businesses in wider shipping market and in the port. Usually, smaller and medium-sized clients, including port forwarding agents, have much more confidence in an independent shipping agent. The reason is in limited services the ship agent can provide, because they are, more or less, focused on ship-port operations. On this basis Zhizhong (2007) sees the opportunity for the medium-small shipping agencies.

\subsection{Container shipping line owned agency}

Besides a strong trend for establishing a joint venture shipping agency, also the trend towards global container shipping lines opening their own agencies in order to provide cost effective and reliable door services is very strong. Their offices can be responsible for port operations or for off-dock terminals as well. The trend is evident along the containerisation industry (Frémont, 2009). At the beginning, such agencies were primarily involved in ship-port operations and procedure, but later on they developed complete services for rail transport out of the ports or vice-versa and road haulage under their control.

Container shipping lines justify these structural changes on the grounds that their main focus is on cutting operational costs, to have better control over their equipment and save some money from agency commission they would pay to an independent shipping agent (Notteboom and Merckx, 2006). According to Parnis (2004), in cases of enough business controlled by the Container lines, their port office can benefit from the economy of size. Such organization gives the opportunity to invest on the market and intensify sales activities. Namely, when the volume of a yearly throughput surpasses 10000 to $15000 \mathrm{TEU}$ it is more convenient for the Container line to have own staff, as agency commission would generate higher costs for agency services.

On the other hand, Container lines must be careful when and how they would like to represent themselves, because with lower volume of containers or cargo costs might exceed income significantly. Such an agency is limited to support itself only by local income, generated by operations as delivery orders, issuing bills of landing, etc. In some cases it can have some extra income from trucking or railing but very often there is no room for any important income.

The actual economic situation bears a negative impact on Container line's business. The volume of containers is rather dropping than increasing. With lower volume of containers the agency lands in red numbers very soon. Such circumstances go in favour of an independent shipping agent. With modern IT technology in use and the increased knowledge of employees, the agent can practically perform the same services as the Container line's office. Even the income originating from an agency-fee structure is gradually reducing, as an independent shipping agent generates extra income from services provided for other
Principals and other shippers or consignees. Provided, of course, they are properly organized and positioned on the market.

\section{Shipping agency market analysis: the case of Slovenian agencies}

\subsection{Market analysis in Slovenia}

A survey of 36 companies that provide shipping agency service or related services in Slovenia has been performed to analyse the present market situation and trends of restructuring of the shipping agency industry. Namely, different market approach of independent shipping agents and Container line's agency office is foreseen, due to increased volume of business and faster organic expansion of Line's offices. On this basis the two main fields of managerial and operational situations have been analysed:

- Owner structure (Principal's or private shipping agency) and joint venture cooperation,

- Organizational and operational situation (just port-ship services or extended services with forwarding/logistics activities).

According to the obtained results 22 companies offer primarily port-ship agency and related services. Of course, they also provide trucking or rail transport for their Principal, but they do not offer these services independently on the market to a wider range of potential customers. Merely three agencies provide dedicated agency services for their principal - Container lines, whereas others represent even more Container lines or other carriers from the bulk market, RO-RO market, oil shipping market, etc.

From the owner structure perspective, among all shipping agents that represent Container lines, only three are owned and managed by the Container lines directly (Figure 1). These are: Maersk Line, Mediterranean Shipping Company and CMA-CGM. The three control the highest share in container throughput at Koper port. A joint venture structure has not been particularly frequent in shipping agencies so far, although according to interviews, some companies lead intensive negotiations to

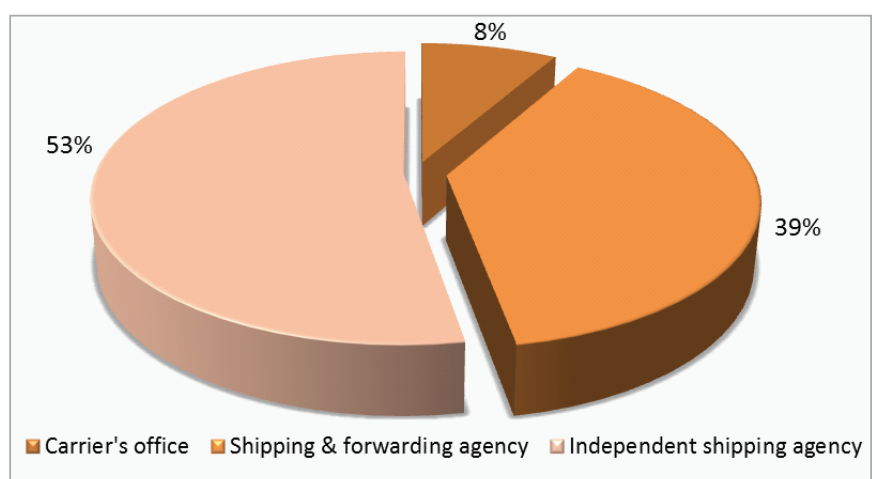

Figure 1 Market share of offices providing shipping agency services 


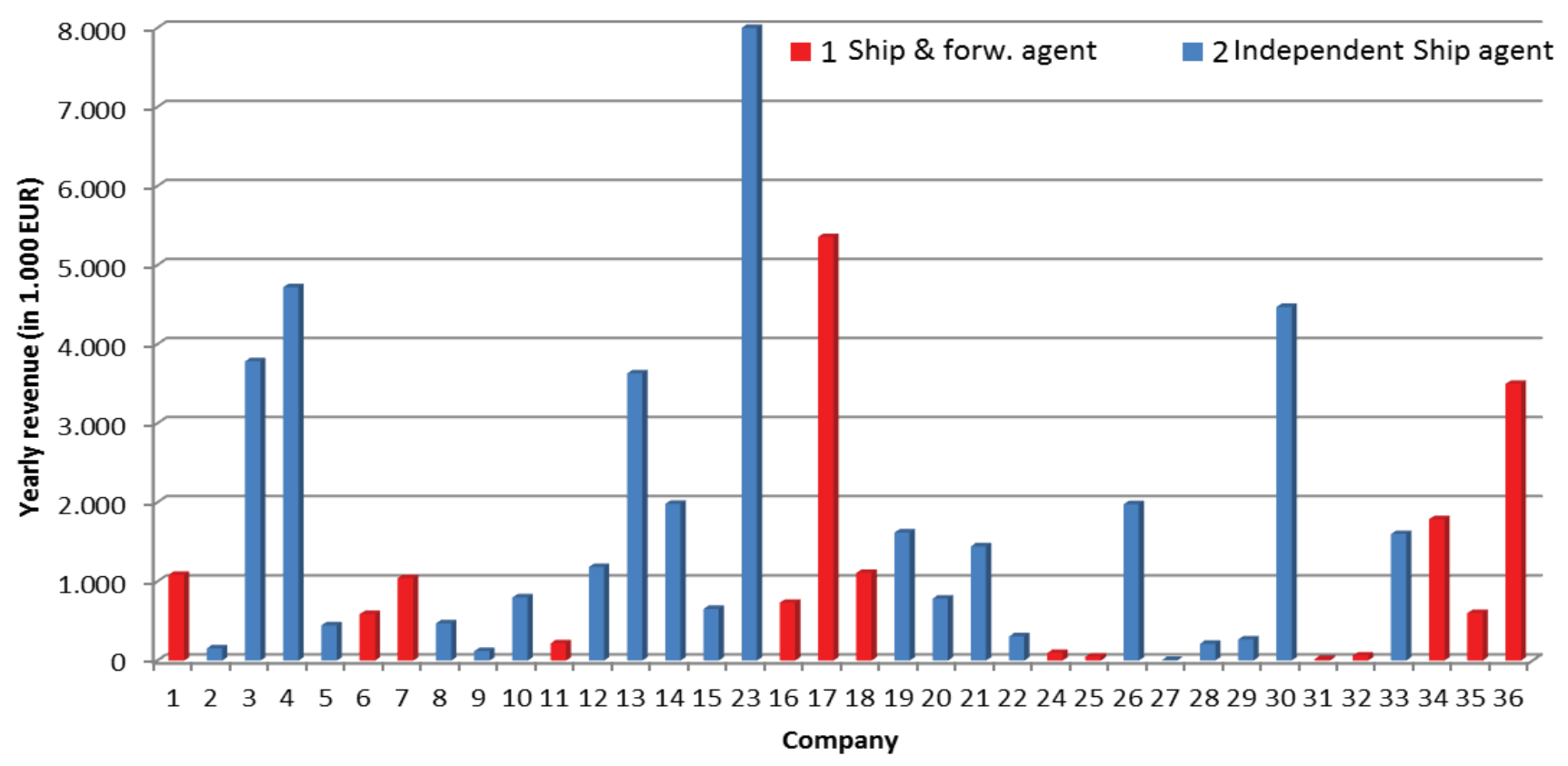

Figure 2 Yearly revenue by pure shipping agencies and agencies offering also forwarding services

agree to such an owner structure with their principals in the near future.

The analysis of yearly revenue shows the dominant market control of just a few agencies (Figure 2). The total revenue generated from shipping agency services is estimated at around 40 million EUR per year, and ranks Slovenian shipping agency sector among smaller markets in EU. Namely, just seven companies have the yearly revenue exceeding 3 million EUR. Among them 5 are pure shipping agencies, representing a Container Line. Two of them offer also forwarding services. On the other hand, 27 companies have yearly revenue below 1.5 million EUR and they hardly compete with the big ones.

According to the obtained data about the number and organization of shipping agencies a decade ago, it can be affirmed that the situation has been changing intensively over the past years. Namely, the number of shipping agencies almost doubled, although around 10 companies closed down their activity at the same time. Presently, $14 \%$ of companies are younger than 5 years and additional $22 \%$ of companies are on the market up to 10 years (Figure 3 ). It is important to stress that $28 \%$ of agencies are on the market for over 20 years. Some of them changed their names and their market orientation over the past years. Such process is driven by new agencies, because they are sales oriented to a specific trade or market (oil, bulk, RORO etc.), with just a few employees. They provide services primarily to a limited number of carriers.

Nowadays, merely three shipping agencies have the same dominant role and market position as in the past (during joint market of Yugoslavia) and they face strong problems in keeping such a market position and status in the local community. They have to compete with new and small agencies for Principals they represent for years, as the trend of decreasing agency commission is inevitably present.

Moreover, Container lines insist on covering the entire logistics chains by themselves, thus an independent shipping agency is disappearing. The trend has become increasingly intensive in recent years. Presently, three Container shipping lines with their offices and three Container shipping lines with dedicated agents control over $90 \%$ of container throughput at Koper port. The pressure on shipping agencies is therefore more than evident, especially because Line's offices perform a range of different logistics services on the local and hinterland markets. They have their offices also in key markets in Central

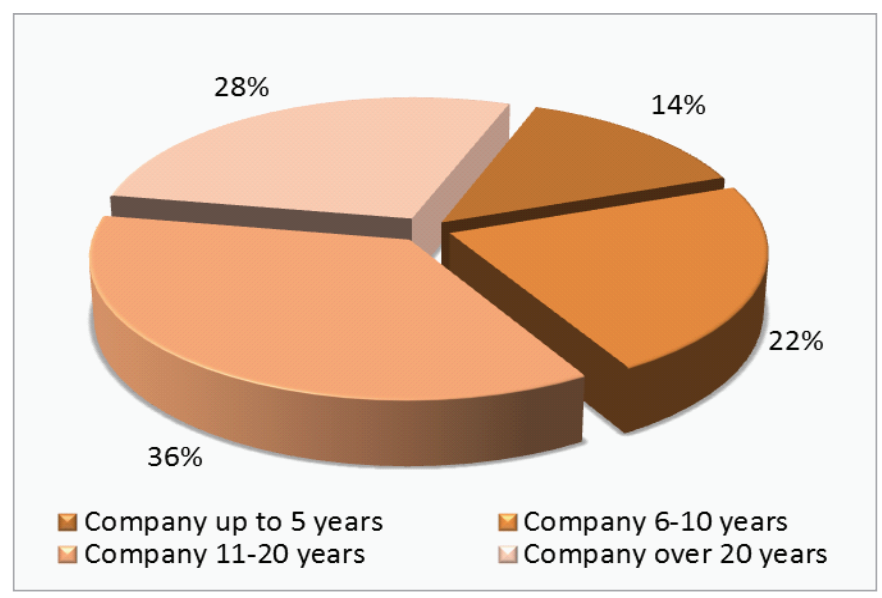

Figure 3 Age of companies offering shipping agency services in Slovenia 


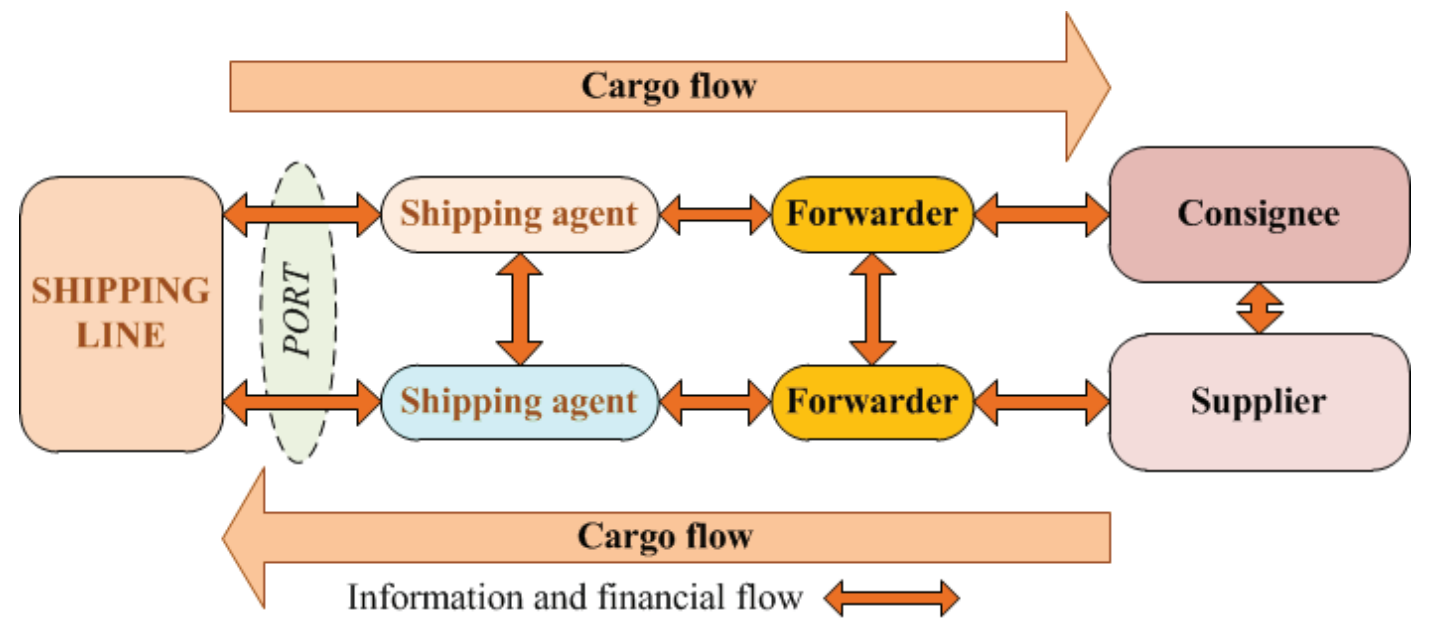

Figure 4 Traditional organization and interactions in a global supply chain

Source: Model worked out by author

Europe such as Hungary, Austria, Slovakia. They operate shuttle-trains from Koper to Budapest, to Dunajska Streda, to Wien etc. They also have a pool of trucking providers and due to economy of scale they obtain competitive trucking rates. With negotiated services on the hinterland terminals, they can leave empty container closer to consignees and vice-versa they can pick-up the empty containers at hinterland depots. Consequently they drastically reduce transport costs. Undoubtedly such set-up brings a lot of advantages to the Line's offices at Koper.

\subsection{Transformation of traditional supply chain organization in container shipping}

Globally, the carriers, which have developed complex logistics services, are in a position to control the entire supply chain (Notteboom and Merckx, 2006). The analysis of such offices in Slovenia shows that they are acting as a forwarder and shipping agent at the same time. Undoubtedly, they try to promote themselves as complete logistics providers. The traditional scheme of a supply chain organization, with seven logistics subjects working in one logistics chain (Figure 4), is under strong pressure with such market strategy. Container shipping line is not offering just ocean transport between two ports, where traditionally shipping agents and port forwarders are used, but would like to control the entire supply chain on the door-to-door basis.

The trend towards reducing logistics subjects like forwarders and shipping agents in the existing organizational structure of logistics chains is present in Slovenia. Namely, Container shipping lines slowly introduce the vertical and horizontal integration in their market activity. Undoubtedly, such a strategy has important and deep impacts on the entire port community and especially on port agents. An agent is forced to transform his role on the market - from shipping agent to a flexible combination of an agent and forwarder. On this basis it can be acknowl- edged that the traditional role of a port forwarder and shipping agent may disappear.

\subsection{Container shipping line's logistics service}

The trend for Container line's port office reorganization is evident also in Slovenia. Today, line owned shipping agency secures a range of operations that were not offered on the market a decade ago, such as:

- Import and export transportation processes, like custom procedures, veterinary and other inspections, etc.,

- Inland haulage, combining different transport modes with a strong focus on the shuttle rail service to their hinterland compounds,

- Complete tracing of units and goods by new IT solutions to end-customers,

- Goods cross-docking to some extent.

Based on the obtained data a scheme of existing Container line's structure and work is presented in Figure 5. The scheme shows a reduction of all "waste interactions" in the logistics chain. This can be secured by new IT solutions and the new commercial knowledge acquired by the port office employees.

Besides internal lean organization and horizontal integration Container shipping lines are in a position to bring pressure on port or terminal operators to obtain agile port services. The increasing yearly volume of containers and goods puts Container lines in a better negotiating position. Moreover, they can secure and benefit from lower port costs for port manipulations and other services.

Container line's port offices are becoming very strong in attracting new business where the inland transport is requested. They can even push intermodal operators into obtaining lower rail transport rates, adjusting timetables of rail services to vessel's arrival or departure from the port and win priority in container delivery. With this, they are able to offer shorter total transit time in doorto-door logistics concept. Moreover, as they have the 


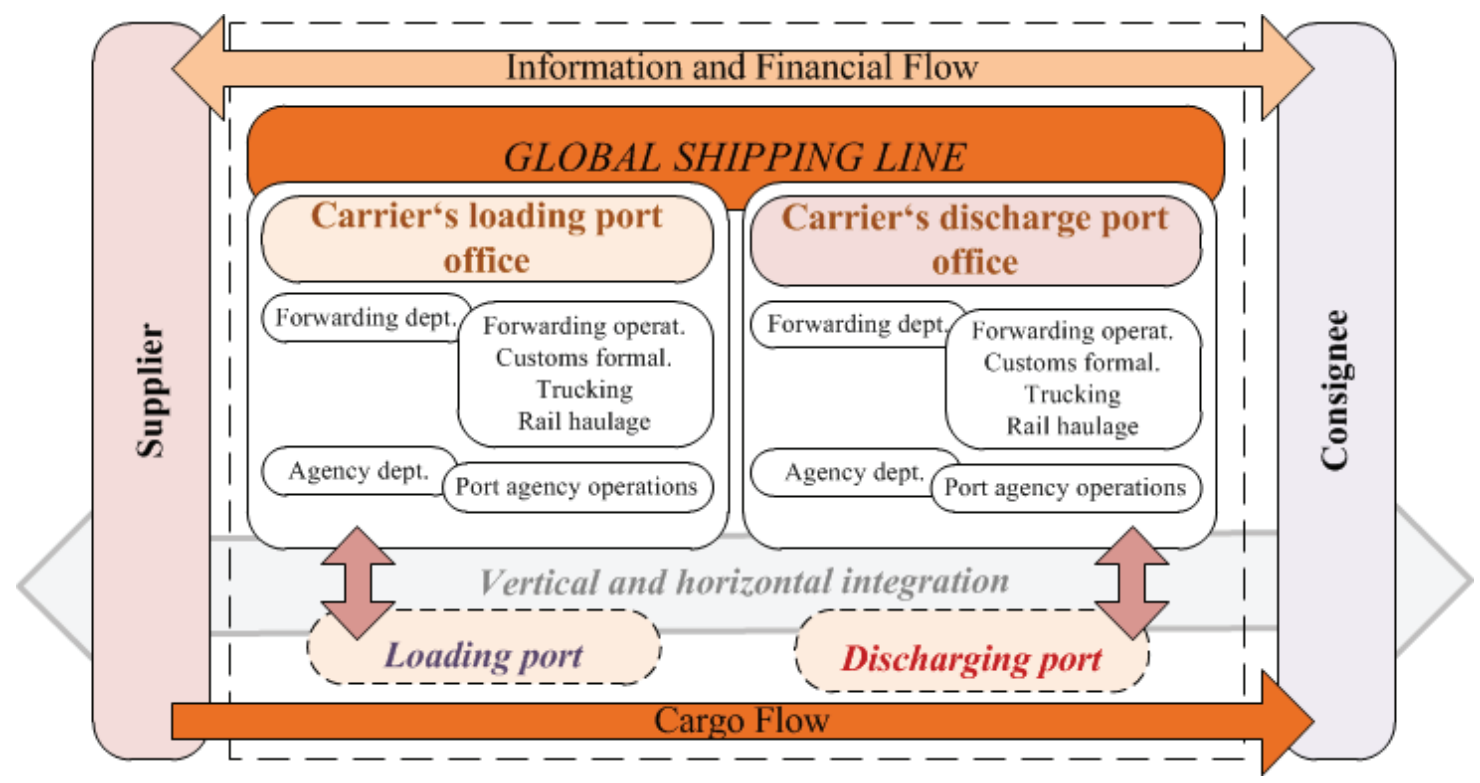

Figure 5 Organizational scheme of Container line's port office

Source: Model worked out by author

control over intermodal equipment, they are in position to leave the empty equipment at the final destination terminal with no additional cost. Such "power" is limiting other port agents and forwarding agents, causing a lack of competitiveness. The trend is present also on the Slovenian market.

The main advantage of Container lines in controlling the entire supply chain is the ability to discount ocean transport rates to VIP clients via special rates by ensuring annual contracts. Port forwarders and other logistics providers face big difficulties to attack such accounts due to the total price un-competitiveness. Undoubtedly, Container lines and their agency office can benefit from their economy of scale.

\subsection{Market situation of independent shipping agents}

Horizontal integration of Container lines and their control over important supply chains have a lot of direct impacts on organization, working procedures and market situation of independent shipping agents. The research within shipping sector in Slovenia highlights the following key elements:

- Sales orientation,

- Transformation from specialization to multi-service providers,

- New skills and knowledge,

- Decreasing income and agency commission.

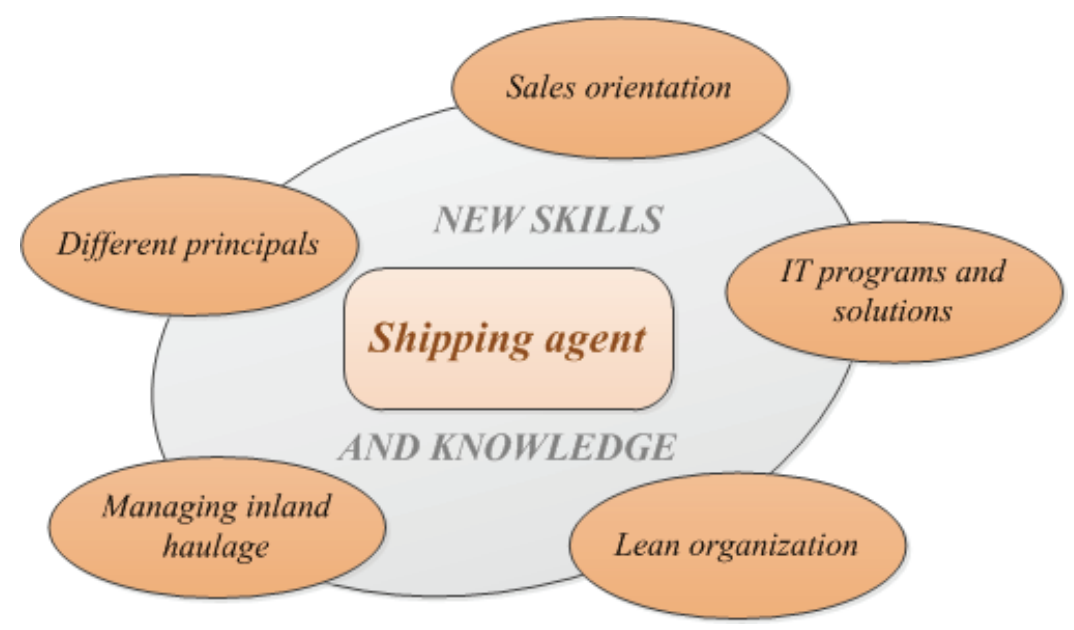

Figure 6 Organizational scheme of Line’s port office 
It has been acknowledged that the elements listed above have important influences on the market's re-organization and transformation. Hence, a lot of shipping agencies offer the extended pallet of logistics services nowadays, including customs services and services related to warehousing of goods. Some of them also entered the sector of LCL (Less Container Loads) or they operate as NVO (non-vessel operators). The process of transformation from specialization on port services to a multi-service provider is evident also through the small number of independent shipping agencies offering just ship-port support. Moreover, the research shows that a trend indicates that Principals contact forwarding agents for the port agency service. They do not prioritize a shipping agent with specialisation on ship-port operations in their pre-selection processes. Such a market attitude was difficult to even imagine a decade or two ago.

For this reason, the orientation of independent shipping agents offering just ship-port service towards finding new business, even from forwarding service, is strongly present, as they are forced to change their way of thinking and find new ways to make their income. Namely, in the past the shipping agent was focused on one Container Line and a few Principals from bulk or liquids sector. Forwarding agents were not their direct competitors but important and reliable clients. With this, it can be affirmed that the horizontal and vertical integration of a shipping sector globally has a significant impact on Slovenian shipping and port community.

The impact of such integration forces the shipping agent to develop new skills and upgrade logistics knowledge (Figure 6). Moreover, additional IT tools must be used, as the entire shipping sector introduces the nonpaper business, where an agent must perform additional operational procedures (electronic manifests for custom authorities, veterinary inspectors, EDI with the port operator, etc.) without being granted any additional commission from the principal.

A pure shipping agent should live from a standard agency commission calculated per unit and from a vessel's representation in the port. According to the data collected from interviews the agent could have lived comfortably from such a standard agency commission, plus whatever they could have earned by other services provided for the principal. No longer than a decade ago, a port agent for tanker principals earned more than thousand dollars per each vessel's port call, where a few documents were required by the authorities and port operator. But today an agent handling tankers can obtain less than half of such commission. Such a trend has been ascertained also by Philips (2005) in his study of EU ship agencies.

The agency commission decreased also for representing the Container lines in the port. During the last decade all Container lines have split the ocean freight into separate charges. Firstly, they introduced a THC (Terminal Handling Charge), which already reduced the ocean rate substantially. Later on different surcharges were introduced where the basic ocean freight was additionally reduced, such as BAF (Bunker Adjustment Factor), CAF (Currency Adjustment Factor), SCS (Ship Security Charge), TSC (Terminal Security Charge), PSS (Peak Season Charge) etc. These decisions influenced the income of an agent drastically, as the percentage on the reduced basic ocean freight remained at the same level.

In addition, instable freights, which have been constantly increasing recently, might help shipping agents to get more income from their commission, but some Principals have changed the contractual agreements where the fixed amount of commission per vessel's call and for handled containers was agreed. Furthermore, in case the Container line organizes the on-carriage or pre-carriage in carrier's haulage, the agent is not entitled to the container handling fee as they were in the past. All these financial aspects of making an income reflect in a rather complex situation of shipping agents offering just ship-port service on the aggressive and quickly developing market.

\section{Developing future role}

\subsection{Container line-owned shipping agency}

It is an inevitable trend that Container lines try to follow global needs of important producers and consumers. Thus, they are forced to provide better services under one umbrella just to satisfy the shippers' expectations. In fact, large Container lines have already established their owned offices at the port of Koper. Namely, Maersk, CMA-CGM and MSC are present with their own agency set-up and the three carriers control $75 \%$ of port's container throughput.

Their offices have already introduced the modern logistics as their market strategy and on this basis they are acting on the local market as a whole logistics provider. The inland transport up to Hungary, Austria, Slovakia and to the Balkans has been brought into sharp focus. They can secure empty pick-up and empty drop-off of their units in all main economic basins. As they control huge quantities of containers on the entire transport route they are able to get competitive inland transport tariffs. Consequently, forwarding agents cannot compete with this model, therefore the major importers or producers in central Europe are already under control of Lines.

It can be predicted that some other Container lines with increasing annual volume of handled containers will follow the strategy of the particular three Lines in the near future. It is to be expected that two to three Container lines might open their own offices very soon. The same strategy in controlling the supply chain flows on the key European markets is foreseen.

The fact is that Line-owned agencies have the future in the shipping market, because Lines can discount ocean rates, port costs, delivery costs and costs related to hinterland terminal manipulation. With the economy of scale they can survive locally as they are not dependent merely on inbound or outbound flows of the local market.

The only problem for the Line-owned shipping agencies might be the drastic decrease of volume or losing 
slots on agreed services. Such circumstances would lead to a decision of closing the office, which may cause extra costs and the benefit from the past period would be decreased significantly. Therefore, Container lines are quite cautious in establishing their direct presence on the small and closed markets as, no doubt, Slovenia with its Port of Koper is. Delnhom (2004) also claims that opening offices in locations where profits are marginal is better left to already present shipping agents in most cases. Consequently, there is still room for independent shipping agents.

\subsection{The need of further market adaption by independent shipping agents}

Although a lot of positive elements of a Container line's agency office have been exposed, the arguments that corroborate the theory that an independent shipping agency has an economic future can be found. An independent shipping agent cannot directly compete with a Line-owned agency, but they must be oriented to a niche business and potentially serve principals and clients from different shipping markets as oil shipping, bulk shipping, etc. An independent agent sees the opportunity in supporting also small and medium size companies, which are of vital importance for the national economy.

Furthermore, many of smaller but still global Container lines and short-shipping carriers are not present in Koper yet. These carriers are usually looking for an independent shipping agent to represent them at the port. Moreover, services deriving from Motorways of the Sea are not present in Koper so far, thus a new business might be further developed in the coming years. According to Jones (2004) this situation is present around EU, where new feeder services are introduced constantly and the rise of Short Sea Shipping and Sea Motorways are leading to redressing the balance in favour of independent shipping agents. From this point of view there is a role for the pure shipping agent in the shipping market.

An independent agent must find niche Principals to represent that are not interested in wider control of supply chain. Such set-up will attract in cooperation forwarding agents that would withhold business from Lines, as Lines might enter into their business directly. These forwarding agents will support an independent shipping agent and Container Line who is not interested in control of the entire supply chain. Consequently, they might benefit from their focus just on port operations and other related services.

Of course, the market presence must be developed as well in order to attract as many small and medium size forwarding agents as possible and to convince feeder carriers for new services to Koper. In Spain such an approach of shipping agents is proposed by González-Torre et al. (2013). Only in this way they will follow the trend of vertical and horizontal integration of shipping industry, which is an inevitable trend also in Slovenian market.

\section{Conclusion}

According to the research results the role of shipping agents has changed drastically in the past two decades. Trends in modern logistics show that Container shipping lines already operate as complete logistic providers, in order to satisfy end-consumers and to transport the commodities on door-to-door basis. The trend of horizontal in vertical integration in global shipping sector is more than evident.

Namely, in small and quite closed markets, as Slovenian market is, the three biggest Container lines have already established their own offices and they provide entire logistics services under their control. The analysis of Slovenian market shows that the three Container lines control over $75 \%$ of total container throughput locally. Taking into consideration that the next three Container lines have a dedicated agent as well, the market share of Line's controlled containers increases up to $90 \%$. All these Container lines provide inland haulage up to key markets in Central Europe and in the Balkans. Based on the cognitions the model of the existing Container line's market role and provided procedures has been presented. The traditional role of seven to nine subjects in the traditional supply chain is more and more replaced by the new model of just three subjects - shipper, Container line and consignee.

Such market re-organization has profound consequences for independent shipping agent's providing just ship-port services on the market. The analysis shows that such shipping agents are disappearing steadily, as they are forced to introduce new services that are usually offered by port forwarding agents. Even if the shipping agent focused on shipport support experiences hard times, the future for them exists. The ship agent must establish a lean organization, increase knowledge and skills on other logistics services, introduce new IT solutions and strengthen their market presence. With this they will be able to attract new business and new Principals, as some of them are not present at Koper yet. Undoubtedly, the shipping agency market in Slovenia and across Europe is under challenge to redefine the agent's role. For this reason, other researches dealing with this topic will be needed also in the future.

\section{References}

[1] Brooks, M.R. (2000) Sea Change in Liner Shipping, Oxford: Pergamon.

[2] Debelic, B. (2013) 'Agency theory and a concession relation in ports open to public traffic in the function of empowerment of entrepreneurial initiatives', Scientific Journal of Maritime Research - Pomorstvo, 27(1), pp. 225-246.

[3] Delnhom, N. (2004) Barwil and Delhom - A Profitable Partnership, BIMCO Centenary General Meeting, Copenhagen, Denmark.

[4] Frémont, A. (2008) Empirical evidence for integration and disintegration of maritime shipping, port and logistics activities (No. 2009-1), OECD/ITF Joint Transport Research Centre Discussion Paper. 
[5] Frémont, A. (2009) 'Shipping lines and logistics', Transport Reviews: A Transnational Transdisciplinary Journal, 29(4), pp. 537-554.

[6] González Torre, P., Sarkis, J. and Adenso Díaz, B. (2013) 'Shipping agents and container management: an exploratory analysis of infrastructural and cost concerns', International Journal of Shipping and Transport Logistics, 5(3), pp. 322-349.

[7] Heaver, T., Meersman, H., Moglia, F. and Van De Voorde, E. (2000) 'Do mergers and alliances influence European shipping and port competition?', Maritime Policy \& Management, 27(4), pp. 363-373.

[8] Heaver, T. D. (2002) 'The Evolving Roles of Shipping Lines in International Logistics', International Journal of Maritime Economics, 4, pp. 210-230.

[9] Jones, S. M. (2004) Is there a future for independent liner agents?, ITIC Forum, London, England.
[10] Lyridis, D. V., Fyrvik, T., Kapetanis, G. N., Ventikos, N., Anaxagorou, P., Uthaug, E. and Psaraftis, H. N. (2005) 'Optimizing shipping company operations using business process modelling', Maritime Policy \& Management, 32(4), pp. 403-420.

[11] Notteboom, T. and Merckx, F. (2006) 'Freight Integration in Liner Shipping: A Strategy Serving Global Production Networks', Growth and Change, 37, pp. 550-569.

[12] Parnis, W. J. (2004) How can a local agent compete with the Global organizations?, BIMCO Centenary General Meeting, Copenhagen, Denmark.

[13] Philips, L. (2005) Industry Challenges - Security Through the Eyes of an Agent, Intertanko AGM, Athens, Greece.

[14] Zhizhong, L. (2007) 'The Marketing Competitive Strategy of the Medium-Small Shipping Agencies'. Journal of Fujian commercial college, 6, pp. 25-36. 